\title{
La mina de José Martín Palacios-Doña Eva (Baños de la Encina, Jaén): la primera explotación minera de la Edad del Bronce documentada en el sureste de la Península Ibérica
}

\author{
The José Martín Palacios-Doña Eva mine (Baños de la Encina, Jaén): the earliest Bronze \\ Age mining activity of the Iberian Southeast
}

\author{
Luis Arboledas Martínez (*) \\ Eva Alarcón García (**) \\ Francisco Contreras Cortés $(* *)$
}

\author{
Auxilio Moreno Onorato (**) \\ Juan Jesús Padilla Fernández $(* * *)$ \\ Adrián Mora González (**)
}

\section{RESUMEN}

Se presentan los resultados de la excavación arqueológica en la mina antigua de José Martín Palacios/Doña Eva (Baños de la Encina). Los resultados confirman y corroboran las hipótesis, planteadas tras los trabajos de campo de 2003 en la cuenca del Rumblar (Jaén), de que la mina tuvo, al menos, dos periodos de explotación: uno en la Prehistoria Reciente (Edad del Bronce) y otro en época romana. Hasta el momento, la mina es la primera del sureste de la Península Ibérica excavada y datada en la Edad del Bronce por carbono 14 y por el material cerámico recuperado. Además se han hallado restos del proceso de reducción metalúrgica (escoria y un fragmento de vasija horno), constatado sólo en tres minas peninsulares más.

\section{ABSTRACT}

This paper presents the results obtained from the archaeological intervention carried out in the ancient mine

(*) Instituto de Historia, Centro de Ciencias Humanas y Sociales, CSIC. C/ Albasanz 26-28. 28037 Madrid.

Correo e.: luis.arboledas@cchs.csic.es

(**) Dpto. de Prehistoria y Arqueología, Universidad de Granada, Facultad de Filosofía y Letras. Campus de la Cartuja s/n.18071 Granada. Correos e.: eva@ugr.es, fccortes@ugr.es, auxiliomoreno@ugr.es

(***) Dpto. de Prehistoria, Universidad Complutense de Madrid, Facultad Geografía e Historia. Edificio B. C/ Profesor Aranguren s/n. Ciudad Universitaria. 28040 Madrid. Correo e.: juanjpad@ucm.es

Recibido: 3-III-2014; aceptado: 4-VIII-2014. of Doña Eva/José Martín Palacios (Baños de la Encina, Jaén). This excavation has allowed us to confirm the hypothesis formulated after the initial campaign, that the mine was exploited in two different phases, the first one during the Bronze Age and the second one in Roman times. This is the first mine in the Southeast of the Iberian Peninsula that has been convincingly assigned to the Bronze Age based both on the recovered ceramic material as well as Carbon 14 results. In addition, we have also found traces of the reduction process (slag, smelting crucibles). These have only been documented at three mines in the Iberian Peninsula.

Palabras clave: Minería del cobre; Reducción del cobre; Edad del Bronce; Cultura de El Argar; Sierra Morena oriental; Mediterráneo occidental; Arqueometalurgia; Estructuración del territorio; Organización del trabajo.

Key words: Copper mining; Copper smelting; Bronze Age; Argaric Culture; Eastern Sierra Morena; Western Mediterranean; Archaeometallurgy; Settlement pattern; Work organization.

\section{INTRODUCCIÓN}

En la última década, un equipo multidisciplinar de investigadores de las Universidades de Granada y Jaén, dirigido por Francisco Contreras, llevó a cabo prospecciones arqueometalúrgicas en el moderno distrito minero de Linares-La Caroli- 
na (Jaén) (1). Como resultado se documentaron numerosos vestigios mineros y metalúrgicos de época antigua, medieval y moderna aún intactos, gracias a que algunas zonas no fueron explotadas intensamente en época industrial. Destaca la documentación, por primera vez, de las rafas (2) de Los Atalayones (Linares), Cerro el Chantre (Linares) y el Polígono (Baños de la Encina), las cuevas mineras de Las Torrecillas (La Carolina), la fundición romana de Fuente del Sapo (Linares) y, sobre todo, la mina de José Martín Palacios/ Doña Eva (Baños de la Encina) (Fig. 1), objeto

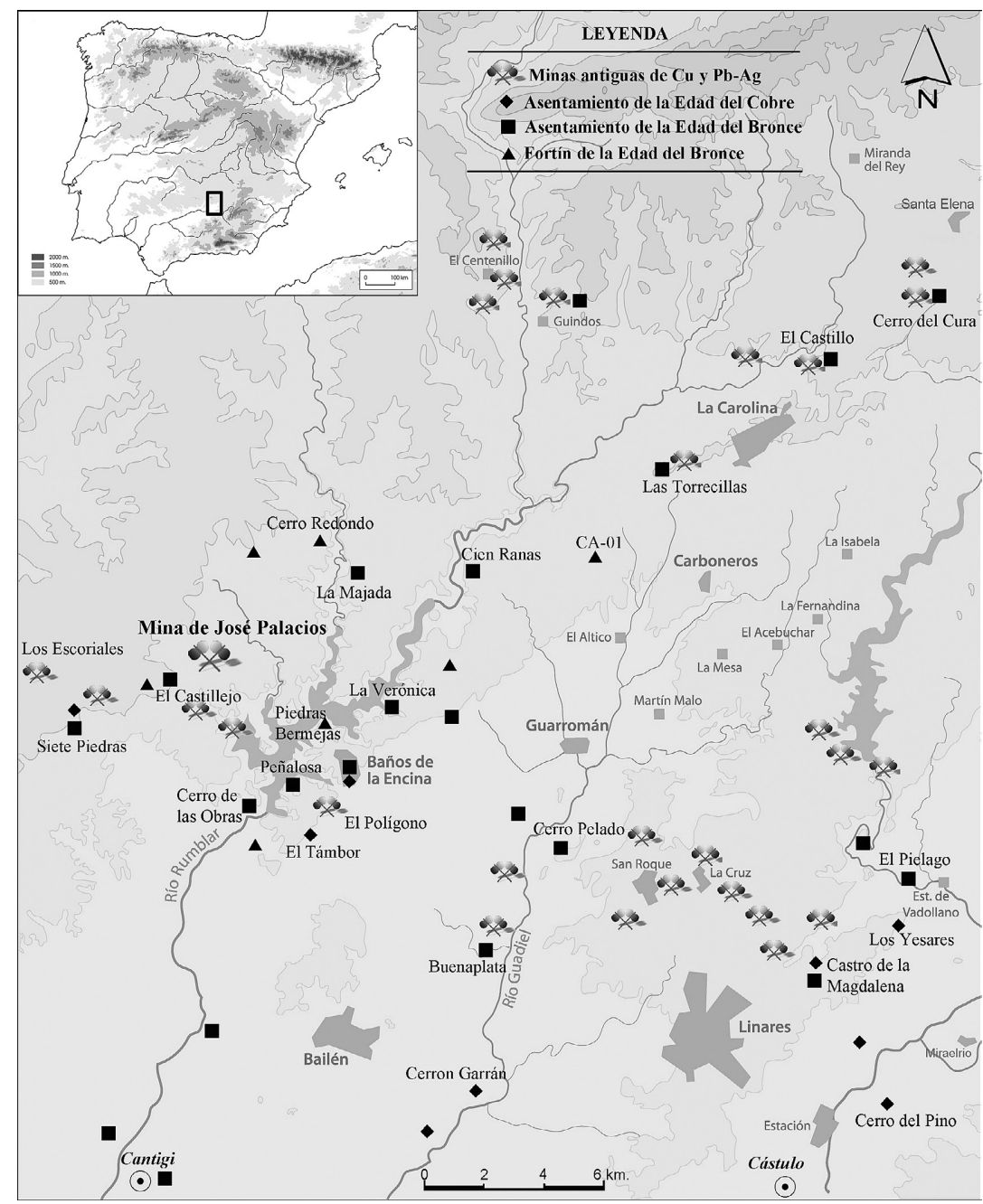

Fig. 1. Localización de la mina prehistórica de José Martín Palacios/Doña Eva (Baños de la Encina, Jaén) y distribución de las principales minas antiguas y yacimientos arqueológicos de la Prehistoria reciente del distrito minero de LinaresLa Carolina (elaboración propia a partir de IdeaVisor, Junta de Andalucía).

(1) Estos trabajos de campo se enmarcan dentro del Proyecto Peñalosa (2 ${ }^{a}$ Fase): "Las sociedades estratificadas de la Edad del Bronce en el Alto Guadalquivir" financiado por la Dirección General de Bienes Culturales de la Junta de Andalucía.

(2) El término rafa es un sinónimo de trinchera minera muy utilizado entre los mineros de Sierra Morena y el sur de la Península Ibérica. de este trabajo (Contreras et al. 2005; Arboledas 2010; Contreras y Dueñas 2010).

Ante el descubrimiento de estos vestigios mineros antiguos, el Proyecto Peñalosa se centró en la excavación del poblado argárico de Peñalosa y en el estudio de las minas del Polígono y José Martín 
Palacios/Doña Eva, dos de las explotaciones con evidencias de explotación prehistórica situadas en sus cercanías (Arboledas et al. 2006; Arboledas y Contreras 2010). El objetivo era investigar todo el proceso minero y metalúrgico de obtención del cobre llevado a cabo por las poblaciones argáricas, desde la extracción del mineral hasta el objeto final.

La mina de José Martín Palacios se localiza en la actual finca de Doña Eva en el término municipal de Baños de la Encina (Jaén), a unos 3 km de distancia sobre plano de esta localidad y a poco más de $2 \mathrm{~km}$ del yacimiento argárico de Peñalosa (Fig. 1). Se documentó en 2003, durante la prospección arqueometalúrgica en la cuenca media y alta del río Rumblar (Contreras et al. 2005). En 2005 se llevó a cabo el levantamiento topográfico del cerro y una prospección del subsuelo mediante tomografía eléctrica (3). El objetivo era observar la disposición de los diferentes elementos que componen la mina y obtener imágenes del subsuelo que identificaran posibles excavaciones subterráneas. Los magníficos resultados obtenidos indicaban la explotación de la mina en época antigua, al menos durante la Edad del Bronce y en época romana (Arboledas et al. 2006; Arboledas et al. 2008). También confirmaban su explotación en época argárica los resultados de los análisis de isótopos de plomo realizados a restos metalúrgicos localizados en contextos domésticos del poblado de Peñalosa y a muestras del mineral recuperado en la mina. A su vez la consistencia entre los resultados analíticos de los diferentes grupos de muestras recogidas en el poblado minero-metalúrgico Peñalosa con los de las cercanas minas de El Polígono y José Martín Palacios sugería que sus habitantes se abastecieron allí de mineral (Jaramillo 2005; Arboledas et al. 2006; Hunt et al. 2011).

La corroboración arqueológica de estos resultados se logró en agosto de 2013 gracias a la intervención en la mina de José Martín Palacios enmarcada dentro del Proyecto General de

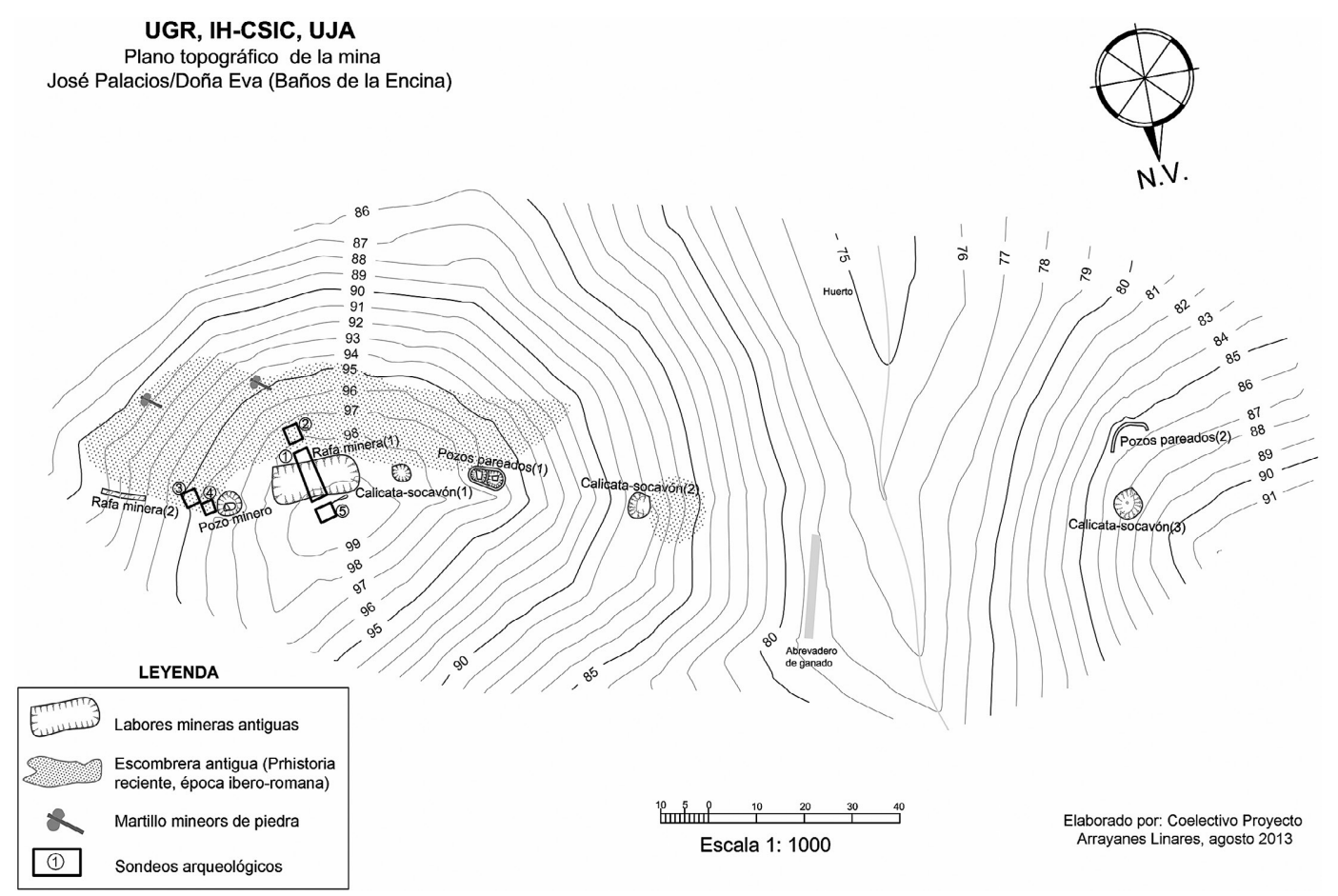

Fig. 2. Levantamiento topográfico del cerro de la mina prehistórica de José Martín Palacios/Doña Eva (Baños de la Encina) con la ubicación de las labores mineras y los sondeos arqueológicos.

(3) Peña, J. A. y Teixidó, T. 2005: Tomografía eléctrica en la 'Mina de Doña Eva'. Informe inédito, Dpto. de Prehistoria y Arqueología, Universidad de Granada.
Investigación de la Junta de Andalucía que estamos ejecutando y financiada por el Ministerio de Economía y Competitividad (proyecto $\mathrm{I}+\mathrm{D}$, 
HAR2011-30131-C02-01) y el Ayuntamiento de Baños de la Encina. Consistió en la excavación de 5 sondeos de diferentes dimensiones en el cerro y la limpieza de uno de los pozos documentados en la prospección (Fig. 2). Los Sondeos 1, 2 y 5 se alinearon en un eje longitudinal con dirección $\mathrm{N}-\mathrm{S}$, separados por testigos de $2 \mathrm{~m}$ en la ladera sur del cerro y cortando parte de la escombrera y de una rafa minera. El objetivo era obtener una lectura estratigráfica completa de la cultura material recuperada en la excavación de la rafa, el relleno y la escombrera para caracterizar cronoculturalmente esta explotación minera. El Sondeo 3 se planteó sobre la misma escombrera asociada a la entrada del pozo y el 4 justo en su boca para determinar la relación entre este pozo y la rafa minera, así como su cronología.

\section{LAS LABORES MINERAS DE LA MINA DE JOSÉ MARTÍN PALACIOS}

La mina se ubica en un pequeño cerro adehesado de más de una hectárea, entre los arroyos de la Plata al Este y del Murquigüelo al Oeste, en la falda nororiental de la elevación granítica del Navamorquin y muy cerca del cortijo de la finca que le da nombre (Fig. 3) (UTM: 428431/4229603). Esta área se enmarca en el distrito minero de Linares-La Carolina, en las estribaciones más orientales de Sierra Morena.

Geológicamente, el cerro ocupa una zona de contacto entre los granitos del Navamorquin (batolito de los Pedroches) y los esquistos-pizarras del Primario (Ordovícico, Silúrico y Devónico). En la superficie afloran areniscas metamorfizadas (o meta-arenitas) con esquistos y pizarras alteradas intercaladas cuyo buzamiento es aproximadamente vertical y una dirección E-O. En las mismas labores se observan las vetas de composición cuarzosa de grosor variable, encajadas en las pizarras. Los materiales aflorantes presentan pátinas superficiales de malaquita y azurita. Las pizarras contienen altas concentraciones de malaquita paralelas a los planos de exfoliación. La mineralización siempre se disemina de manera discontinua sobre la roca de caja y la veta (Contreras et al. 2005: 28).

La morfología del paisaje adehesado de esta finca, dedicado al pastoreo de ganado bovino, no

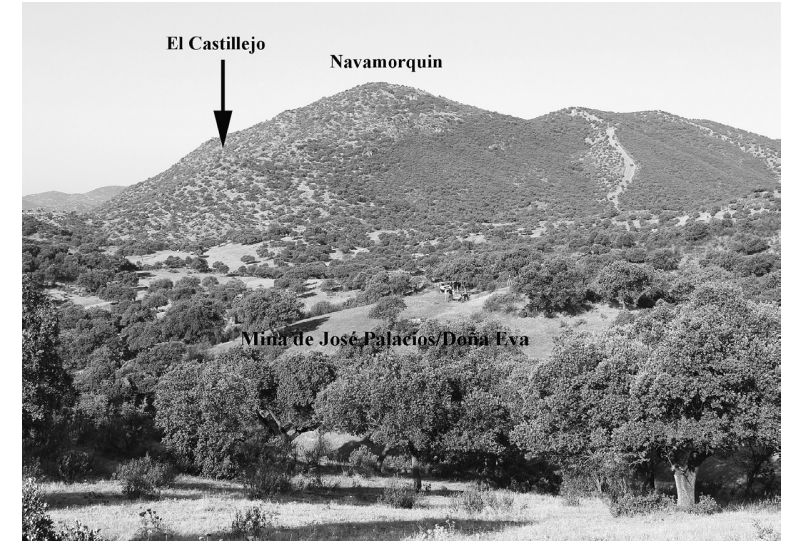

Fig. 3. Vista panorámica de la mina prehistórica José Martín Palacios/Doña Eva (Baños de la Encina). Al fondo se observa el cerro granítico de Navamorquín y el poblado argárico del Castillejo.

ha sido nunca alterada ni por labores agrícolas, ni por explotaciones mineras posteriores a las estudiadas. Gracias a ello, durante los trabajos de campo previos a la excavación, se han documentado en superficie de Este a Oeste del cerro hasta 7 labores mineras antiguas que explotaron este pequeño filón en toda su longitud (Contreras et al. 2005; Arboledas et al. 2008) (Fig. 2).

La primera es una importante rafa de más de $30 \mathrm{~m}$ de longitud por unos $3 \mathrm{~m}$ de anchura media situada en la falda oriental del cerro (Fig. 2). Está totalmente colmatada y mimetizada en el paisaje por procesos postdeposicionales naturales y antrópicos. En superficie se identifica por una inflexión en el terreno y un afloramiento de esquitos de la pared sur de la trinchera.

Ladera arriba, contactando con la anterior, hay un pequeño pozo con una boca de planta rectangular muy irregular de $1,80 \mathrm{~m}$ por $1,20 \mathrm{~m}$. Estaba casi colmatado de escombros y chatarra. Su limpieza pretendía reconocer la morfología del pozo y de las posibles galerías asociadas, así como documentar posibles restos arqueológicos y huellas de explotación que ayudaran a caracterizar esta labor minera. De momento, la intervención, concentrada en la retirada de la basura y escombros que colmataban el interior, ha permitido reconocer su trazado hasta una profundidad de $11,50 \mathrm{~m}$. Seguramente continúe en profundidad y conecte con alguna galería como parece indicar la humedad de los rellenos en este punto y los 
resultados de la tomografía eléctrica practicada en este cerro en 2005. El trazado del pozo es muy irregular desde su entrada. Su planta e inclinación varía según los tramos, intercalando anchurones con rampas casi verticales. Esta traza es producto de una explotación anárquica del recorrido del filón en profundidad, posiblemente en diferentes momentos históricos. En las paredes, se observan las improntas de mineralización de cobre, huellas de pico y un orificio posiblemente producto de un puntero. El material arqueológico recogido en la escombrera revela que fue excavado en época romana pero tal vez su origen se remonte a la Edad del Bronce, al igual que las rafas.

Siguiendo el filón hacia el Oeste se documentó una explotación a cielo abierto, de más de $3 \mathrm{~m}$ de ancho por casi $15 \mathrm{~m}$ de longitud, colmatada por completo e integrada en el paisaje (Fig. 2). Sobre esta trinchera se planteó un sector de excavación, cuyos resultados analizaremos extensamente en el siguiente apartado.

La siguiente labor, a $10 \mathrm{~m}$ al Oeste en la cima del cerro, es una depresión circular superficial de $3 \mathrm{~m}$ de diámetro que puede ser un pozo totalmente colmatado o un pequeño socavón o calicata (Fig. 2). Otra calicata de similares características se localiza en la ladera Oeste del cerro, a $10 \mathrm{~m}$ al Oeste de la primera pareja de pozos pareados (Fig. 2).

Además de las trincheras, destaca el hallazgo de dos parejas de pozos de planta cuadrada (Fig. 2). La primera estaba formada por dos pozos (1,5 m de lado) excavados sobre el filón y separados del mismo por un testigo de poco más de un metro. Las paredes muestran pizarras altamente meteorizadas en cuyos planos de exfoliación hay lentes de cuarzo con malaquita. La segunda pareja de pozos (poco más de un metro de lado) se sitúa en la otra margen del Arroyo del Pilar. Al contrario que los anteriores se disponen de forma perpendicular al filón. Actualmente, se encuentran totalmente cegados y no se observan en superficie (Contreras et al. 2005: 29).

Este tipo de pozos, conocidos como gemelos o pareados, se han adscrito a época romana. Son muy comunes en la Faja Pirítica Ibérica, donde se han documentado importantes concentraciones como las más de 800 parejas en el paraje de Cabezas del Pasto (Sotiel Coronada, Huelva) y las 245 del Cabezo de los Silos (La Zarza, Huelva) (Domergue 1983: 15-16 y 158-161, 1990). Esta tipología es menos frecuente en Sierra Morena aunque existen algunos ejemplos en la provincia de Córdoba, como en Las Tobosas (Hinojosa), La Solana (Belacázar), Chaparro Barrenado (Alcaracejos) y Calamón (Posadas) (García Romero 2002: 266). Hasta el momento, las dos parejas de pozos gemelos de la mina de José Martín Palacios son las únicas constatadas en el moderno distrito de Linares-La Carolina (Arboledas et al. 2008).

Por último, una escombrera de grandes dimensiones, esparcida por la ladera sur y este del cerro, se asocia a estas labores mineras. En los terreros se observan materiales procedentes de la roca caja (esquistos, areniscas metamorfizadas y pizarras) y de la veta (cuarzo, barita, malaquita, azurita y óxidos de hierro). Durante los primeros trabajos de campo se recuperaron dos martillos mineros y cantos de río de un material no muy común en el entorno, empleados tanto para las labores de extracción como en el procesado del mineral extraído (Arboledas et al. 2008).

\section{RESULTADOS DE LA EXCAVACIÓN. LOS RESTOS MINEROS PREHISTÓRICOS}

Los objetivos generales de la intervención eran dos. El primero, conocer la forma y trazado en profundidad del pozo y la rafa 1 de la mina de José Martín Palacios y documentar evidencias arqueológicas (huellas en la roca de las herramientas, materiales empleados como piedra, cerámica, metal, etc.)- que permitieran definir y datar las fases de explotación. Y el segundo determinar las técnicas extractivas empleadas en cada momento.

\subsection{Rafa minera 1 y escombrera, Sondeo 1}

El Sondeo 1 de planta rectangular $(10,50 \times 3$ $\mathrm{m}$ de lado), planteado en la zona superior de la ladera sur del cerro, ha documentado un sector de la rafa 1 y de la escombrera asociada (Fig. 4A). La cerámica y martillos mineros recuperados y los resultados de carbono 14 han corroborado la excavación de esta trinchera minera al menos durante la Edad del Bronce.

El sector excavado de la rafa es de unos $9 \mathrm{~m}^{2}$. No se profundizó más allá de los $5 \mathrm{~m}$ por proble-

Trab. Prehist., 72, N. ${ }^{\circ}$ 1, enero-junio 2015, pp. 158-175, ISSN: 0082-5638

doi: $10.3989 /$ tp.2015.12149 

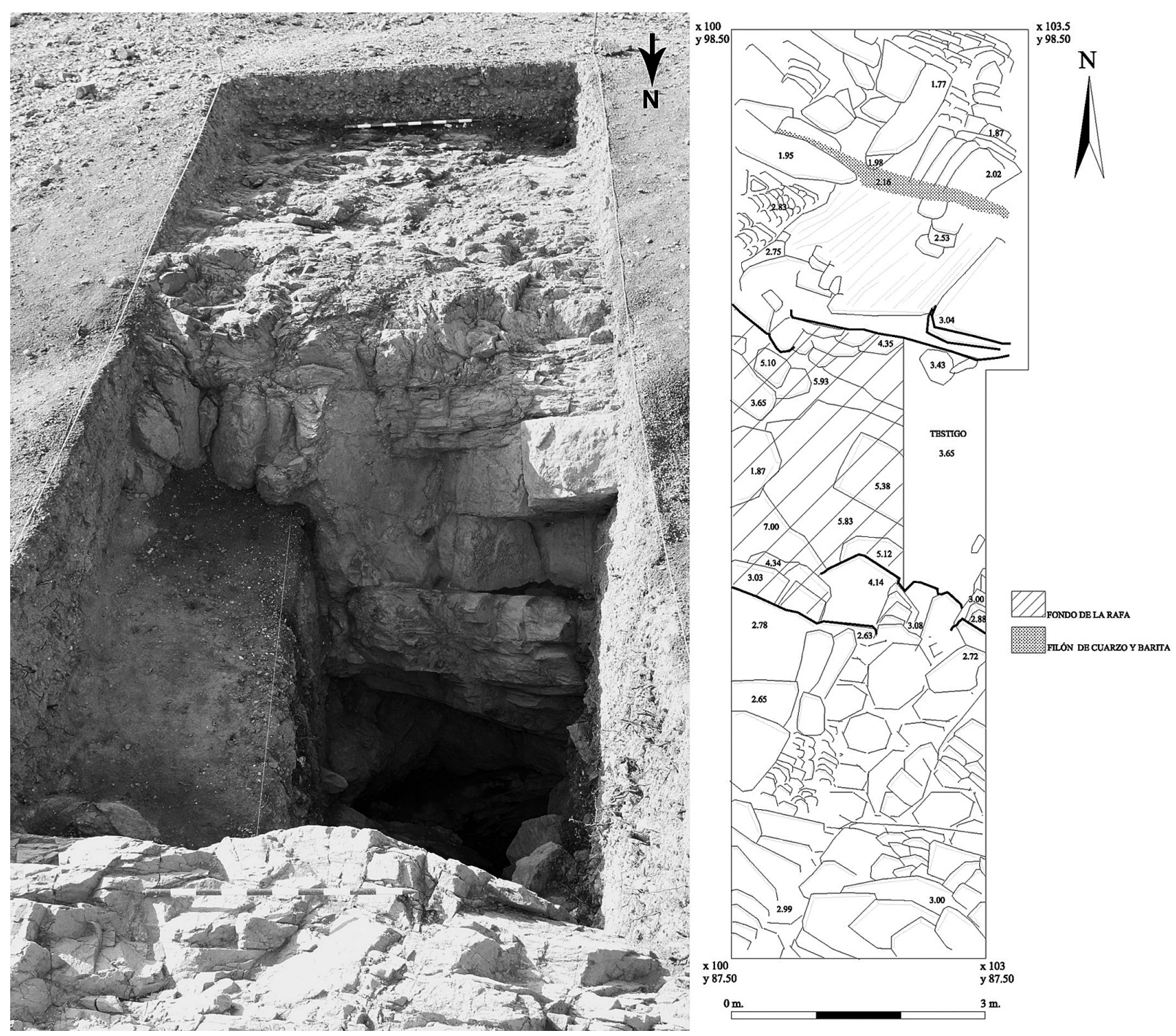

Fig. 4. Trinchera minera 1 y escombrera del Sondeo 1 de la mina prehistórica de José Martín Palacios/Doña Eva (Baños de la Encina): A. (izquierda). Foto de la trinchera minera y la escombrera una vez excavada; B (derecha). Planta final.

mas de seguridad. La trinchera minera es de sección en $\mathrm{V}$ hasta los $3 \mathrm{~m}$ de profundidad con una anchura máxima de 3,40 $\mathrm{m}$ en superficie y de 1,84 $\mathrm{m}$ a base. A partir de aquí, la trinchera profundiza de forma sinuosa con una anchura máxima de 1 $\mathrm{m}$. Esta traza tortuosa y estrecha es consecuencia del vaciado y explotación total del filón encajado entre la roca caja. Es probable que la rafa, a esta profundidad, no continúe hacia el Este, debido a que el filón en este punto se estrecha y se vuelve estéril. En cambio, sí parece seguir con una cierta anchura hacia el Oeste (Fig. 4).
El trazado bastante alterado e irregular, con entrantes y salientes, de las paredes de la roca caja se deben a la explotación de las zonas mejor mineralizadas del filón (Fig. 4B). En superficie no se han observado huellas de herramientas, como por ejemplo de picos, quizás por su alteración. Una pigmentación/coloración oscura bajo un saliente podría corresponder a huellas de empleo de fuego para la extracción del mineral más que a óxidos de hierro. En la pared sur, los restos de pequeñas vetas de baritas mineralizadas de cobre e hierro conservados prueban la existencia de un 
filón mineralizado y certifican a su vez claramente que la explotación minera es antigua.

Diferentes estratos con una potencia y granulometría diversa colmataron la rafa. Posiblemente los mismos mineros irían depositando allí los residuos a medida que profundizaban para evitar subirlos al exterior. La granulometría de cada nivel se corresponde con los residuos de los procesos de trituración y selección que se llevarían a cabo a pie de mina. Bajo el nivel superficial se suceden hasta 7 estratos, compuestos básicamente por gravas. Varios de ellos contenían grandes bloques de esquistos mineralizados de cobre de la roca caja (Fig. 5). En el perfil estratigráfico se observa diferente grado de buzamiento en los estratos. En general, en la mitad sur su deposición es bastante horizontal, mientras que en la zona norte, fundamentalmente en los niveles inferiores, buzan algo hacia el N. Esto indicaría que, sobre todo la parte más profunda de la rafa, se fue colmatando desde el lado norte de la mina por el vertido de los residuos, así como por los procesos postdeposicionales naturales.

En todos los rellenos aparece gran cantidad de mineral de cobre desde pequeños fragmentos a grandes bloques de esquistos, abandonados por su peso en la parte inferior de la rafa. Además en los niveles intermedios cerca de la superficie se han recuperado 1 fragmento de cerámica a mano, 1 base de orza típica de época argárica (UEN 9) (Fig. 6A, 4) y 5 fragmentos de martillos mineros de piedra con parte de la ranura central (UEN 2) (Fig. 6B, 10-13). Dichos restos confirman una fase inicial de explotación de la mina en los primeros momentos de la Edad del Bronce, ateniéndonos a la fecha de C14 de la escombrera (abajo).

La cerámica a torno encontrada y la segunda muestra de C-14 (nº 1017-UEN 12) (Fig. 5, Tab. 1) con fecha calibrada entre el 543-366 cal BC para los niveles medios e inferiores excavados indican la colmatación de parte de la rafa en época ibérica. Posiblemente se estuvieran localizando filones metalíferos por esta zona en relación con los poblados ibéricos del borde de la Depresión Linares-Bailén. Sí parece clara la reanudación de la explotación en época romana como certifican algunas cerámicas rodadas comunes y los pozos gemelos.

La escombrera, excavada en un sector de $12 \mathrm{~m}^{2}$ justo en las inmediaciones de la trinchera, sólo presentaba $50 \mathrm{~cm}$ de potencia, en contra de lo esperado a tenor de las dimensiones de la

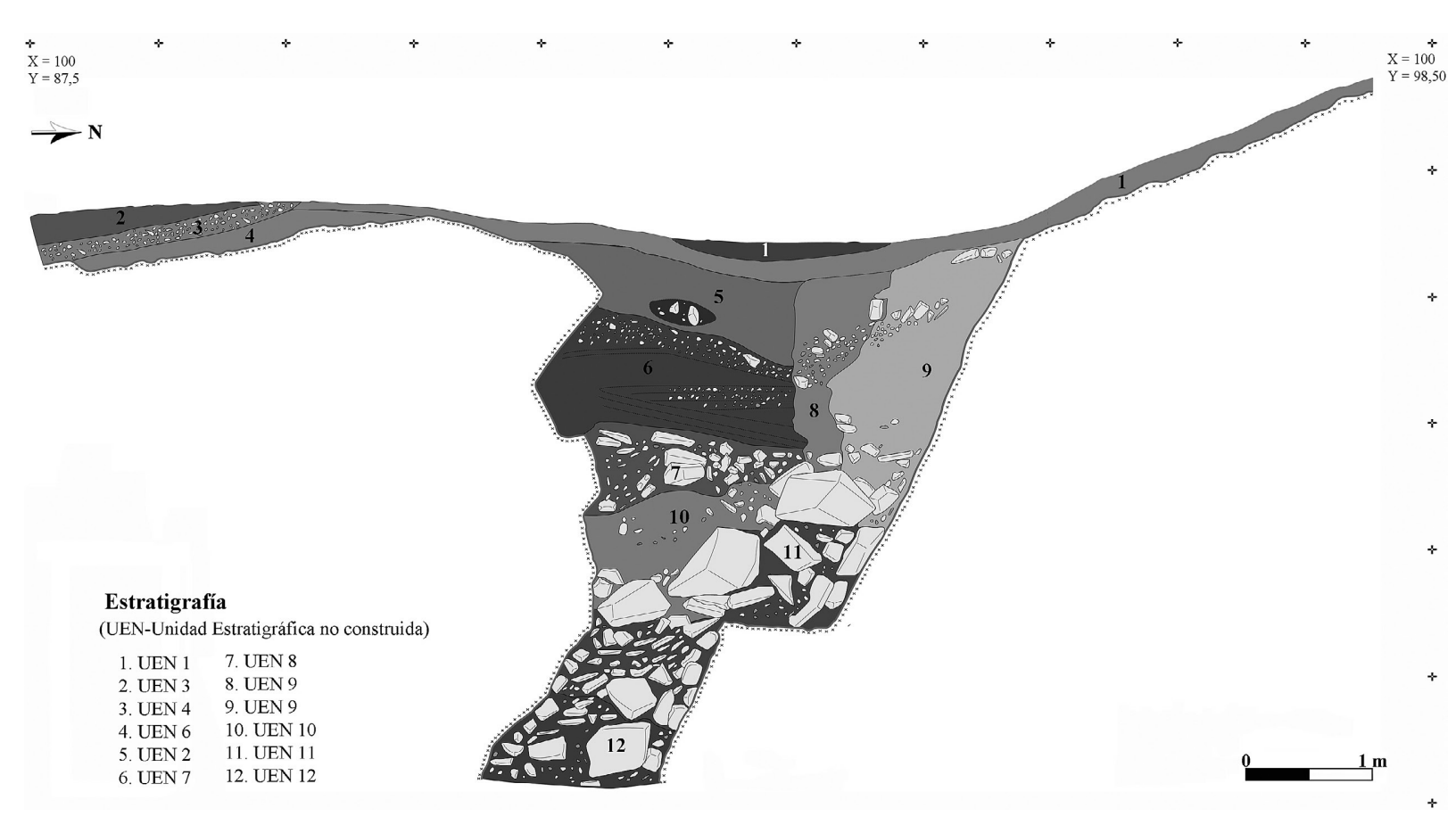

Fig. 5. Mina prehistórica de José Martín Palacios/Doña Eva (Baños de la Encina). Sondeo 1: perfil oeste de la trinchera minera 1 y la escombrera.

Trab. Prehist., 72, N. ${ }^{\circ}$ 1, enero-junio 2015, pp. 158-175, ISSN: 0082-5638

doi: $10.3989 /$ tp.2015.12149 


\begin{tabular}{|c|c|c|c|c|c|c|c|}
\hline $\begin{array}{c}\text { Codigo } \\
\text { laboratorio }\end{array}$ & Material & Contexto & $\begin{array}{c}\text { Fecha } \\
\text { convencional BP }\end{array}$ & \pm & $\delta 13 C$ & $\begin{array}{l}\text { Fecha calibrada }(1 \sigma) \\
(68 \% \text { probabilidad }) *\end{array}$ & $\begin{array}{c}\text { Fecha calibrada } \\
(2 \text { sigma }) \\
(95 \% \text { probabilidad })\end{array}$ \\
\hline CNA-1004 & $\begin{array}{l}\text { Carbón de } \\
\text { rosácea }\end{array}$ & $\begin{array}{l}\text { UEN 6, } \\
\text { nivel inferior } \\
\text { escombrera, } \\
\text { Sondeo } 1\end{array}$ & 3726 & 31 & $-16.74 \%$ & 2196-2029 cal BC & 2205- $2030 \mathrm{cal} \mathrm{BC}$ \\
\hline CNA-1017 & $\begin{array}{l}\text { Carbón de } \\
\text { rosácea }\end{array}$ & $\begin{array}{c}\text { UEN 12, } \\
\text { interior Rafa } \\
\text { 1-Sondeo } 1\end{array}$ & 2359 & 41 & $-21,29 \%$ & 488-389 cal BC & $\begin{array}{l}730-691 \mathrm{cal} \mathrm{BC} \\
659-651 \mathrm{cal} \mathrm{BC} \\
543-366 \mathrm{cal} \mathrm{BC}\end{array}$ \\
\hline CNA-4006 & $\begin{array}{l}\text { Carbón de } \\
\text { rosácea }\end{array}$ & $\begin{array}{c}\text { UEN 6, } \\
\text { relleno } \\
\text { interior Rafa } \\
\text { 2-Sondeo } 4\end{array}$ & 2695 & 32 & $-18,85 \%$ & $894-810$ cal BC & 903- $805 \mathrm{cal} \mathrm{BC}$ \\
\hline
\end{tabular}

Tab. 1. Resultados de los análisis de C14 realizados en el CNA (Centro Nacional de Aceleradores) a tres muestras procedentes de esta mina (inéditos).

* Para la calibración a $1 \sigma$ de las dataciones se ha utilizado el programa OxCal (v.4.2) (Bronk Ramsey 2009) y la curva de calibración IntCal13 (Reimer et al. 2013).

explotación minera. Los estratos buzan hacia el sur siguiendo la pendiente de la ladera. Como se ha indicado, puede que su escaso grosor se deba a que los mineros, redujeran esfuerzo y tiempo, vertiendo el material sobrante, alguno de grandes dimensiones, sobre la misma rafa.
En la secuencia estratigráfica se diferencian bien 3 estratos de desecho de explotación con gran cantidad de mineral de cobre. Destaca sobre todo el último, un estrato compacto de tierra limo-arcillosa que cubre la roca y correspondería al nivel superficial prehistórico y antiguo de inicio
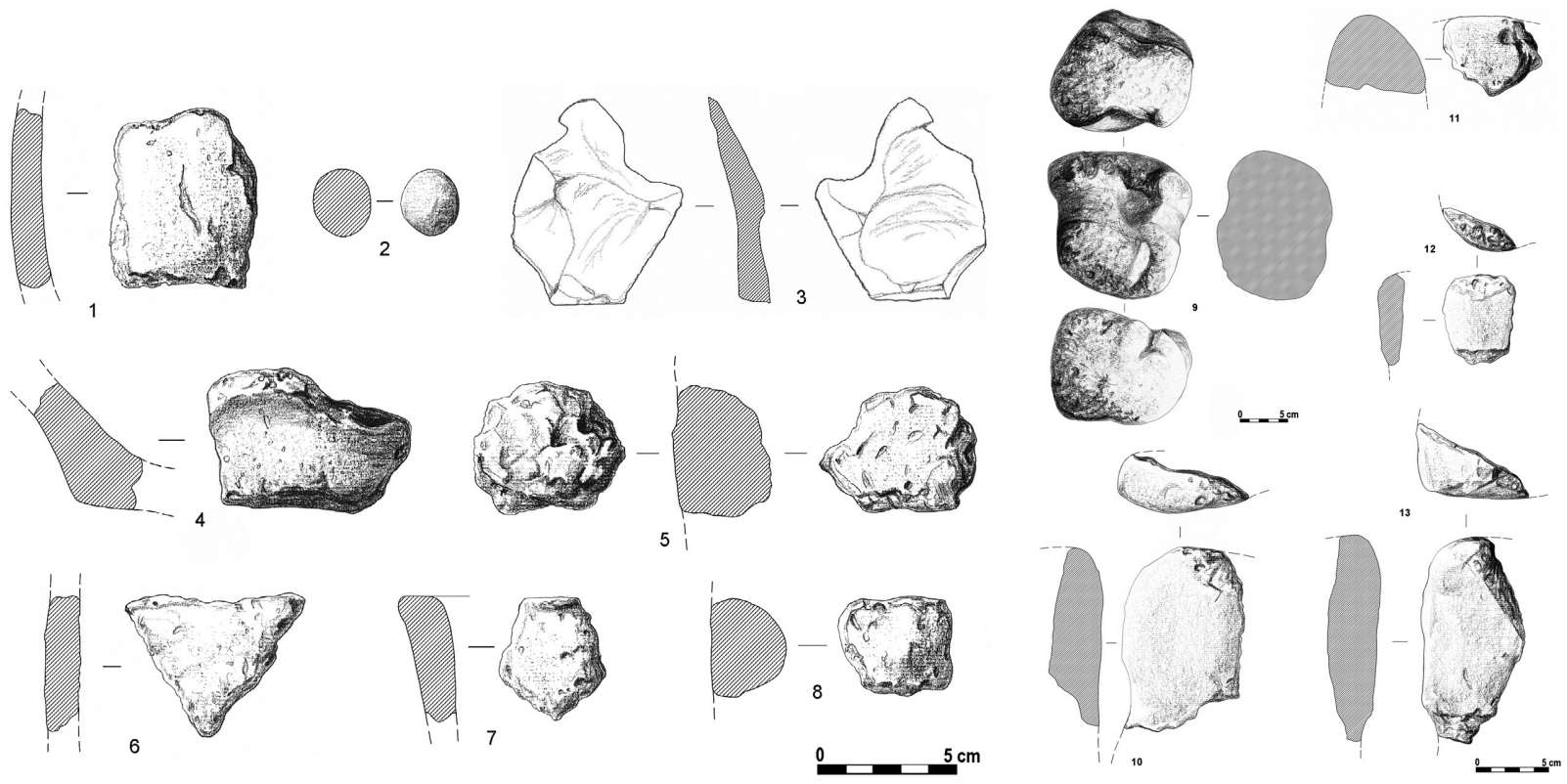

Fig. 6. Cerámica (1 y 4-8) y material lítico (2, 3, 9-13) de la Edad del Bronce de la mina de José Martín Palacios/Doña Eva (Baños de la Encina): 1, 6, 8 fragmentos indeterminados, 3 lasca de silex, 4 base de orza, 5 fragmento de vasija de reducción, 7 borde plano de olla, 2 bola de piedra pulimentada, 9-13 martillo minero con acanaladura y fragmentos de otros. Proceden del Sondeo 1 escombrera $(1,6)$ y trinchera $(4,10-13)$, del Sondeo 2 escombrera $(5,9)$ y del Sondeo 5 $(2,3,7$ y 8$)$.

Trab. Prehist., 72, N. ${ }^{\circ}$ 1, enero-junio 2015, pp. 158-175, ISSN: 0082-5638 doi: $10.3989 /$ tp.2015.12149 
de esta labor. Se han recuperado del mismo dos fragmentos indeterminados de cerámica a mano de la Edad del Bronce (Fig. 6, 1-2) y dos muestras de carbón de arbustos de la familia de las rosáceas. La $n^{\circ}$ 1004-UEN 6 marca el inicio de la escombrera y, por ende de la trinchera, entre 2205 cal BC-2030 cal BC (Tab. 1), es decir, en una fase antigua de la Edad del Bronce.

En definitiva, la propia tipología de esta pequeña labor minera (trinchera), los martillos recogidos durante la prospección y posterior excavación, los análisis de isótopos de plomo de los minerales $\mathrm{y}$, sobre todo, la fechas de C14 y la cerámica a mano procedente de la escombrera y del interior de la rafa demuestran claramente su apertura y explotación en época argárica. Tras su abandono la mina se fue colmatando de manera antrópica y natural. En época ibérica se encontraría parcialmente colmada como corrobora una de las fechas de C14. El hallazgo de cerámica romana indica la explotación del filón y la frecuentación de este cerro durante esta época.

\subsection{Escombrera antigua, Sondeo 2}

El Sondeo 2 está alineado con el 1 del que le separa un testigo de $2 \mathrm{~m}$. Ocupa $10,5 \mathrm{~m}^{2}$ en la escombrera, buscando completar la sección de la rafa y recabar datos sobre la formación del desmonte (Fig. 2). Se confirmó la escasa potencia del vertedero de esta mina (menos de $50 \mathrm{~cm}$ ) y el vertido de residuos del proceso de extracción del mineral. En este sondeo se han diferenciado los mismos tres estratos que en el anterior. En el primer estrato se halló un martillo minero de piedra con ranura central para el enmangue. Pesa $2,5 \mathrm{~kg}$ y mide $15 \mathrm{~cm}$ de longitud y $13 \mathrm{~cm}$ de ancho (Fig. 6B, 9). En el nivel inferior de limos se recuperó un pequeño fragmento perteneciente a una vasija de reducción con la superficie interior escorificada, igual a los numerosísimos ejemplares hallados en los diversos ámbitos excavados de Peñalosa (Fig. 6A, 5).

La presencia de este fragmento de vasijahorno típica de la Edad del Bronce y de otro con escoria adherida en la cima del cerro son pruebas evidentes de que, al menos a pie de mina, se realizaban ensayos metalúrgicos previos al transporte del mineral a los poblados. Hasta el momento es la primera vez que se evidencia esta práctica en una mina prehistórica del sur peninsular: en la zona de Sierra Morena oriental sólo se conocía en el interior de los poblados. La cronología de este material está en consonancia con la del hallado en el Sector 1 y con la fecha de C14.

\subsection{Rafa minera 2 , Sondeos $3-4$}

Los Sondeos 3 y 4 se trazaron sobre una escombrera asociada a un pozo para determinar su relación con la posible rafa de la ladera este del cerro, además de esclarecer su cronología (Fig. 2, afloramiento). Antes de excavar se retiraron los escombros de la entrada de este pozo para tener una visión más completa de su relación con la escombrera, documentar posibles huellas de trabajo, recoger el material arqueológico si lo hubiera, etc. La escombrera cubría parte de esta segunda rafa y estaba formada por 4 niveles de desechos mineros procedentes de la excavación del pozo.

El nivel inferior que sellaba la rafa, mucho más limoso y compacto que el resto, cubría la roca y sellaba la rafa. Correspondería al estrato superficial formado tras el abandono y amortización de la trinchera y previo a la explotación del pozo. De esta escombrera del pozo proceden 1 fragmento de molino romano, 1 borde de cerámica común de un/a jarrito/jarra de cuello estrecho y borde recto con labio ligeramente engrosado al interior, varios indeterminados de cerámica común romana y 9 fragmentos de cerámica de pasta beige, con decoración a peine de bandas paralelas muy típica de la cerámica ebusitana, de época tardo-antigua/ bizantina (segunda mitad siglo VI y siglo VII d.C.). En conjunto, el material nos proporciona una cronología poco concreta para la escombrera que se extiende desde el Alto Imperio a época tardo-antigua.

El Sondeo 4, debajo de la escombrera del pozo, documenta un tramo de la rafa minera 2 de $1 \mathrm{~m}$ de anchura máxima en el flanco Este. Hacia el Oeste se estrecha hasta cerrarse junto al pozo debido a que el filón se vuelve estéril, mientras $1 \mathrm{~m}$ más al Oeste vuelve a estar fuertemente mineralizado siendo explotado a través de un pequeño pozo minero (Fig. 7). Por su

Trab. Prehist., 72, N. ${ }^{\circ}$ 1, enero-junio 2015, pp. 158-175, ISSN: 0082-5638

doi: $10.3989 /$ tp.2015.12149 


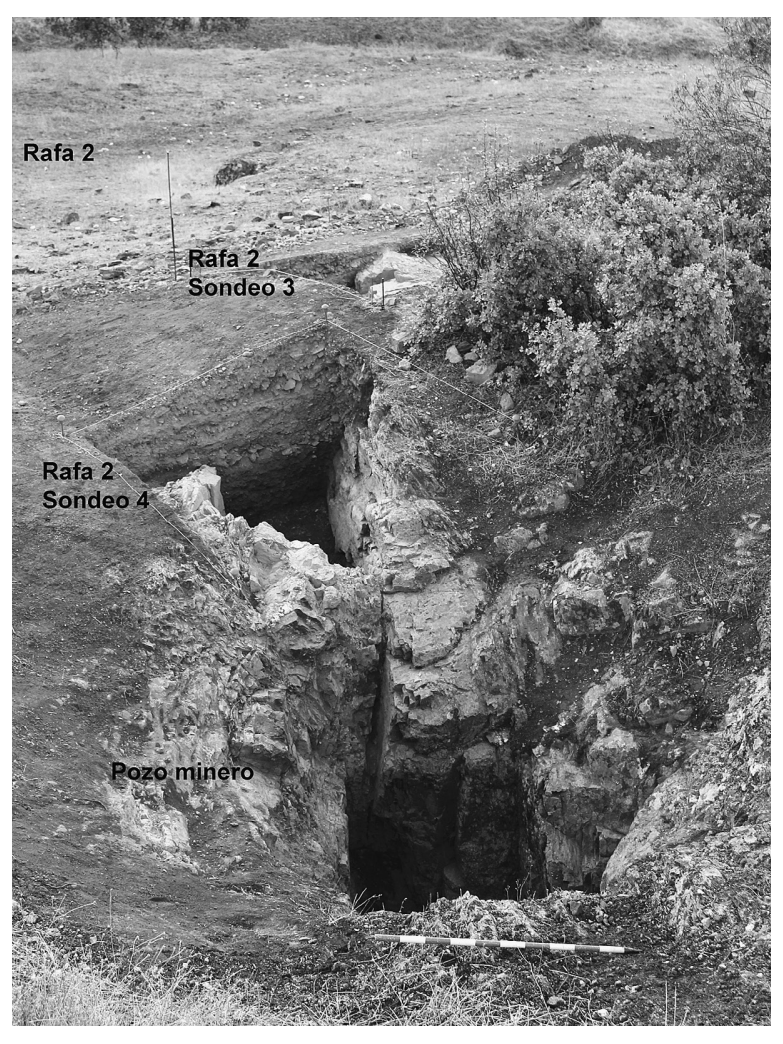

Fig. 7. Trinchera minera 2 de los Sondeos 3 y 4 de la mina prehistórica de José Martín Palacios/Doña Eva (Baños de la Encina).

parte, la trinchera continua hacia el Este, ladera abajo, ensanchándose como se ha comprobado en el Sondeo 3 y en la inflexión que el afloramiento de esquistos dibuja sobre el terreno. Las paredes de la trinchera, a pesar de la alteración que han sufrido, presentan aún restos de mineralización de cobre, fundamentalmente, malaquita.

El interior de la rafa, excavado hasta $1 \mathrm{~m}$ de profundidad, estaba colmatado por 3 depósitos de gravas y canchales de pequeños clastos, entre los que se documentaron numerosos fragmentos de mineral de cobre. Los estratos, identificados por sus diferentes tonalidades de marrón, buzan ligeramente siguiendo la pendiente de la ladera. Son estériles arqueológicamente por lo que desconocemos cuando cesó y se colmató la explotación. La datación por C14 de una pequeña muestraa de carbón ( $n^{\circ}$ 4006-UEN-6) recogida en el último estrato excavado sitúa la colmatación de la parte media/alta de la trinchera entre 903 cal BC -805 cal BC, en el Bronce final- periodo orientalizante.

En resumen, y a tenor del material arqueológico recuperado, la excavación del pozo en época romana formó este vertedero y selló la rafa previa, seguramente, de la Edad del Bronce. Con este periodo se relacionan otros restos mineros de similares características, como la rafa del Sondeo 1. La trinchera estaría colmatada antes de la explotación del pozo en época romana como demuestra la fecha de carbono 14 de uno de los estratos del interior y la ausencia de material arqueológico en los rellenos.

\section{Evidencias de ocupación, Sondeo 5}

Planteamos el Sondeo 5 de $9 \mathrm{~m}^{2}$, en la cima del cerro, alineado con el 1 y el 2 (Fig. 2). El objetivo era comprobar si había evidencias de una posible ocupación estacional de los mineros que laboraban estas minas. La excavación alcanzó la roca natural a unos $70 \mathrm{~cm}$ y ofreció algunos datos relevantes, aunque el material arqueológico fue exiguo. Las 3 unidades sedimentarias registradas, nada tenían que ver, ni en composición ni en textura, con los estratos excavados en los restantes sondeos. Bajo la cobertura vegetal superficial, había 2 niveles limo-arcillosos, muy compactos (UENs 2 y 3), que rellenaban los huecos de la roca aflorante y regularizaban la superficie. En ambos se recuperaron restos de cultura material: fragmentos pequeños de mineral de cobre, dos trozos muy pequeños de galena, una lasca de sílex (Fig. 6A, 3), una bola de piedra pulimentada (Fig. 6A, 8) y un fragmento amorfo de cerámica a mano (Fig. 6A, 6). En la cerámica de época argárica destaca un borde plano de una olla típica del periodo (Fig. 6A, 7) y un fragmento de vasija de reducción con restos de escoria adheridos.

A nivel estructural, no se han identificado restos arqueológicos interpretables como estructuras positivas o negativas. Sin embargo planteamos la posibilidad de que estos niveles fueran superficies de uso/trabajo en época argárica por la gran compacidad de ambos estratos, su disposición horizontal sobre una base rocosa tan irregular y su contenido arqueológico. Todo ello nos viene a demostrar al menos la frecuentación/ocupación 

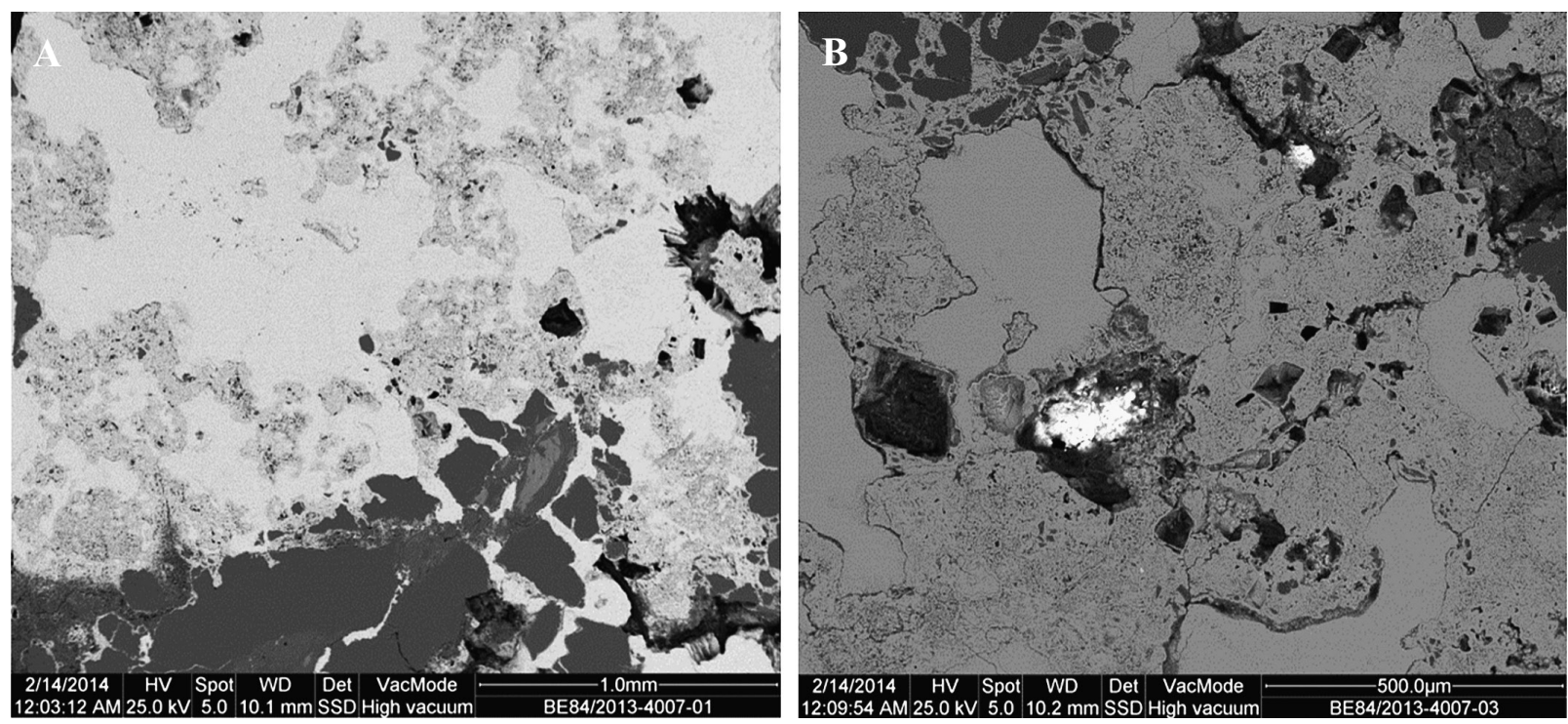

Fig. 8. Mineral ferrocuproso procedente del interior de la rafa minera 2-Sondeo 4 de la mina de José Martín Palacios/ Doña Eva (Baños de la Encina). A. Aspecto general de la muestra. Las rocas de color gris oscuro son ganga de cuarzo. La matriz blanca continua es predominantemente óxido de cobre. Las zonas blancas porosas son óxidos de hierrocobre. Se ha detectado una inclusión de óxidos de hierro-estaño; B. Detalle de las zonas cupríferas donde se aprecian inclusiones de baritina en color blanco.

de este cerro durante la Edad del Bronce, ya sea como campamento estacional en relación con los trabajos mineros o como espacios productivos de los mineros procedentes de los yacimientos argáricos cercanos. En este caso, el poblado más próximo es El Castillejo, situado escasamente a $1,5 \mathrm{~km}$ al Oeste.

\section{ANÁLISIS DE LOS RESTOS MINERO- METALÚRGICOS}

Hasta el momento se han analizado mediante microscopio electrónico de barrido (4) un resto de mineral de cobre y un fragmento de vasija

(4) Los análisis MEB han sido realizados por Salvador Rovira, Auxilio Moreno y Martina Renzi en los laboratorios del Museo de Ciencias Naturales del CSIC de Madrid utilizando un microscopio Fei Inspect con detector de electrones secundarios, electrones retrodispersados y un detector de Catodoluminiscencia Mono CL Gatan, y que dispone de un sistema de análisis integrado Oxford Instruments Analytical-Inca. El equipo ha sido operado por la microscopista Marta M. Furió. cerámica con escorificación interna, recuperados durante la excavación:

El fragmento de mineral del Sondeo 4 ( $n^{\circ}$ 4007) es ferrocuproso (5) (Fig. 8A) con inclusiones de óxidos de hierro-estaño y baritina (Fig. 8B). La proporción de estos elementos aún no ha sido determinada por análisis cuantitativos de las muestras. Si bien una de las inclusiones observadas en la muestra a través del MEB contiene un $30,3 \%$ de hierro y un $60,7 \%$ de estaño. El análisis de la ganga identifica rocas de cuarzo y barita, algo que ya se preveía al observar restos de estas vetas, apenas mineralizadas, en las paredes de la rafa 1. Este tipo de ganga, muy frecuente en los filones mineralizados de esta zona minera de Sierra Morena, servía como fundente durante el proceso de fundición sin que fuera necesario añadirlo de forma intencionada como se

(5) Aunque por convención internacional el cobre se analiza como $\mathrm{CuO}$, en realidad se encuentra en forma de otros compuestos químicos oxídicos (cuprita, malaquita, etc.). El MEB no permite diferenciarlos pero sí la microscopía óptica por el color, combinando campo claro y campo oscuro. 

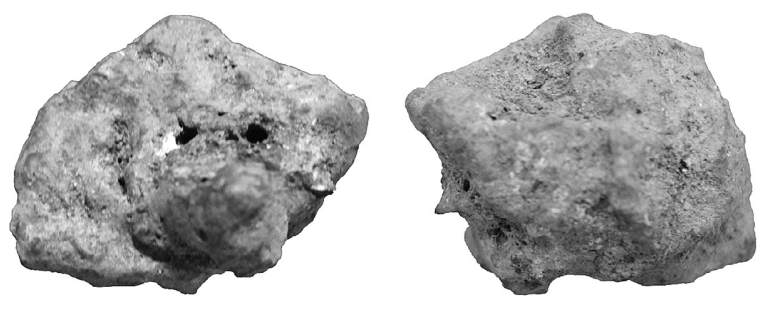

0 $5 \mathrm{~cm}$

Fig. 9. Fotos de ambos lados del pequeño fragmento de vasija cerámica de reducción recubierto de escoria procedente del Sondeo 5 de la mina de José Martín Palacios/ Doña Eva (Baños de la Encina).

documenta en periodos posteriores en esta zona (Arboledas 2010).

La vasija cerámica con escorificaciones (BE84-2013-5005/1) procede del Sondeo 5 (Fig. 9). Es un pequeño fragmento amorfo de cerámica que tiene adherida en su pared interna una generosa capa de escoria que ha dado resultados muy interesantes para la comprensión del proceso de transformación del mineral extraído de esta mina en concreto (Fig. 10). Las características formales del fragmento son como las documentadas en Peñalosa y otros poblados argáricos que jalonan el valle del Rumblar. Sin embargo contiene algunos aspectos raramente observados antes en los yacimientos estudiados y que merece la pena destacar. La estructura fayalítica difiere de los piroxeninos habituales de las escorias y escorificaciones calcolíticas y de la Edad del Bronce de la Península Ibérica, lo que, por otra parte, casaría perfectamente con la muestra de mineral analizado. Este mineral ferrocuprífero, y por tanto autofundente, contiene la proporción de óxido de hierro necesaria para reaccionar con la ganga silícica y

Fig. 10. Muestra de la vasija de reducción procedente del Sondeo 5 de la mina de José Martín Palacios/Doña Eva (Baños de la Encina): A. Bola de cobre puro recubierta por una gruesa capa de sulfuro de cobre. Se aprecian segregados de bismuto en color blanco; B. Detalle de la superficie de la escoria. La corrosión ha destacado los cristales de fayalita, probablemente por disolución del vidrio de relleno intersticial; C. Detalle de una zona con abundante magnetita y bolas de metal de diferente tamaño.
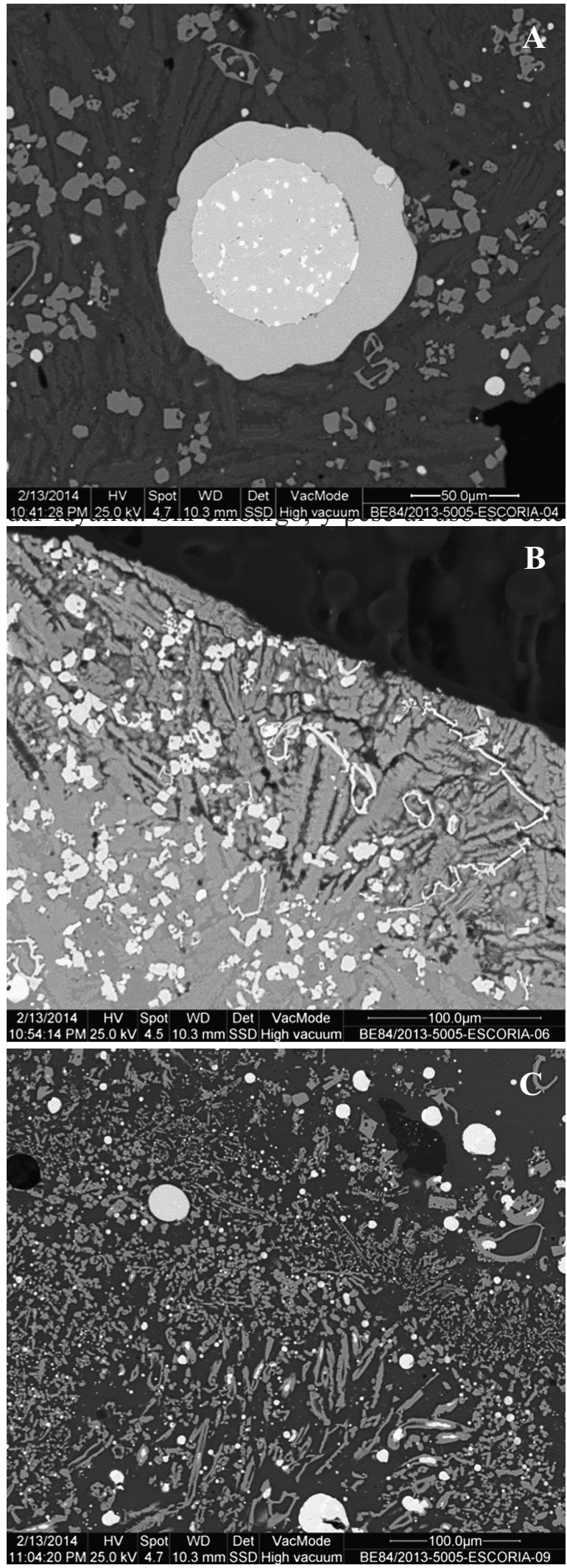
tipo de mineral, las condiciones de trabajo de la vasija de reducción son demasiado inestables para aprovechar esa ventaja. La superabundancia de magnetita refleja una ambiente excesivamente oxidante. Eso se traduce en que, si bien la matriz fayalítica estaba fundida a unos $1.150^{\circ}$ $\mathrm{C}$, la magnetita era una carga sólida que aumentaba considerablemente la viscosidad global de la escoria y, como consecuencia, el cobre neoformado no conseguía separarse fácilmente por gravedad. Si las condiciones hubieran sido más reductoras no se habría formado magnetita y el óxido ferroso hubiera reaccionado con toda la ganga y con los silicatos de la cerámica para dar fayalita y liberar el cobre. Ello lejos de parecer un aspecto negativo, es una evidencia más de que la tecnología de la vasija de reducción cumplía ampliamente sus necesidades.

Las mejoras tecnológicas que supone el empleo de minerales autofundentes o fundentes de manera intencionada no se constata hasta la llegada de los fenicios a las costas de la Península Ibérica. Se piensa que la utilización de fundentes debió de ocurrir en la Prehistoria de Oriente Próximo, aunque por el momento no existan evidencias arqueológicas. En consecuencia, la muestra jienense es un ejemplo más de la utilización, por los metalúrgicos de la Edad del Bronce, de minerales autofundentes sin que por ello haya que entenderla como una acción intencionada para facilitar el proceso de fundición.

\section{CONCLUSIONES}

Los resultados de la excavación en la mina de José Martín Palacios confirman las hipótesis planteadas tras los primeros trabajos de campo (Arboledas et al. 2008) y los análisis de isótopos de plomo practicados a minerales de esta mina y restos metalúrgicos de Peñalosa (Hunt et al. 2011). Esta mina fue explotada al menos en dos periodos diferentes, la Prehistoria Reciente (Edad del Bronce) y la época romana, mediante dos sistemas bien diferenciados: las labores a cielo abierto (trincheras y rafas) y los pozos y galerías respectivamente.

La explotación de este pequeño filón se iniciaría durante la Prehistoria Reciente con la excavación de trincheras a cielo abierto (la del Sondeo
1 y la de los Sondeos 3 y 4), beneficiándose, básicamente, los afloramientos superficiales del filón, ricos en minerales de cobre. Hasta donde se detuvo la excavación, las dimensiones de las dos trincheras difieren mucho en función de la potencia del filón en esas zonas del cerro. Este sistema de laboreo se caracteriza por ser una práctica minera simple, sencilla y muy rentable, "de rapiña". Esta técnica perduraría durante la Antigüedad, sobre todo, en época romana republicana, e incluso la practicarían también las pequeñas cuadrillas de mineros de Sierra Morena hasta los años 1960.

En la extracción del mineral se emplearían diferentes herramientas de madera, hueso y piedra. Es probable que también se utilizara el fuego. El sistema consistía en calentar la roca a temperaturas muy elevadas para después enfriarlas con agua lo más rápido posible, produciendo grietas y fisuras en la pared, gracias al principio de dilatacióncontracción. El empleo de esta técnica (Moreno et al. 2010) se confirma en el yacimiento de Peñalosa donde los fragmentos de mineral procedentes de la mina El Polígono tienen evidencias de haber estado expuestos al fuego, así como en otras minas prehistóricas de la Península Ibérica como La Profunda (León) (Blas 1996, 2007-2008).

Normalmente, en el registro arqueológico sólo se conservan útiles líticos, como machacadores sobre cantos de río y martillos mineros, recogidos en las escombreras vinculadas a estas labores y en el relleno de las mismas. Los martillos suelen ser de una roca dura como la diorita $\mathrm{u}$ ofita y tener ranura central para enmangar un cabo de madera unido por un cordaje. Por todo el sur peninsular encontramos numerosos mazos como los documentados en estas minas que se han adscrito a la Edad del Bronce por sus similitudes con los hallados en el yacimiento de Peñalosa. Su tipología no varía desde la Prehistoria Reciente hasta época romana republicana pero, en la mina de José Martín Palacios, aparecen asociados estratigráficamente a niveles argáricos.

Los fragmentos de cerámica a mano y bruñida, típica de la cultura argárica, así como los de vasija-horno, hallados en las escombreras y el interior de las labores sí son un fósil guía indiscutible para asociar estos vestigios a la Edad del Bronce. Otro elemento indicativo de esta época es la lasca de sílex recuperada en el Sondeo 5. En tercer lugar, los resultados de los análisis de isótopos

Trab. Prehist., 72, N. ${ }^{\circ}$ 1, enero-junio 2015, pp. 158-175, ISSN: 0082-5638

doi: $10.3989 /$ tp.2015.12149 
de plomo realizados a minerales de esta mina y a restos metalúrgicos de Peñalosa determinaron su consistencia, confirmando que esta mina junto a la del Polígono fueron dos de las que abastecerían de mineral a este yacimiento metalúrgico de la Edad del Bronce (Hunt et al. 2011) (6). Por último, el análisis de C14 de la muestra procedente de la parte inferior de la escombrera corrobora esta cronología. Las otras dos muestras de C14 indican que se colmataron a partir del Bronce Final y época ibérica, una vez explotadas estas labores mineras en época prehistórica. Pero no sabemos hasta qué punto se trata de unos rellenos de colmatación antrópicos, producto de la frecuentación/ explotación de esta mina en estos periodos, o de un rellenado natural del interior. Por la textura de los estratos y la ausencia de material arqueológico parece corresponder con estratos naturales de derrumbes y sedimentación.

Hasta el momento, las minas de José Martín Palacios y del Polígono (Arboledas y Contreras 2010) son las únicas de Sierra Morena, e incluso del sureste de la Península Ibérica, adscritas fehacientemente a la Prehistoria Reciente tanto de forma directa por la cultura material recuperada en los trabajos de campo (cerámica, martillos de piedra), como a través de las analíticas realizadas (isotopos de plomo y dataciones de C14). En el resto de la península se conocen muy pocos ejemplos de minas que con cierta seguridad fueran explotadas antes de la Edad del Hierro. En su mayoría se concentran en la región astur leonesa: El Aramo (Dory 1893: 337 y 362), El Milagro (Asturias) y La Profunda (León) (Blas 1996, 2007-2008; Blas y Suárez 2009). A estas se pueden sumar la mina de Moçissos (Portugal) (Hanning et al. 2010: 289), la galería de Riner en Lérida (Montero Ruiz 2010) o la mina de La Turquesa en el Priorato tarraconense (Montero et al. 2012). En territorio español no peninsular, se ha documentado recientemente otra pequeña explotación en Sa Mitja Lluna, en la Illa d'en Colom (Es Grau, Menorca) (Llull et al. 2012; Perello et al. 2013). En el resto de Europa destacan entre otras las explotaciones mineras prehistóricas de Kargaly (Chernykh 2004; Rovira y Martinez Navarrete 2005), del Macizo Central francés, como las minas de la región de Cabrières (Ambert 1994; Ambert et al. 1998) o las minas

(6) Según los resultados analíticos existiría una tercera mina como fuente de recursos en Peñalosa aún no localizada. irlandesas de Ross Island (O'Brien 2004) o galesas de Copa Hill (Timberlake 2003: 72). Por último, la mina de Chinflón, en Huelva, que algunos autores situaban en el Bronce Final (Blanco y Rothenberg 1981: 36-51) y otros en época calcolítica (Acosta 1995), según la reciente revisión de Craddock (2013: 420-423) de las dataciones de carbono 14, se explotaría en el Bronce Final a principios del I milenio a.C.

La excavación de la mina de José Martín Palacios ha proporcionado otros datos relevantes como evidencias del proceso metalúrgico a pie de mina, en concreto dos fragmentos de vasija de reducción, típica del registro argárico, como los de Peñalosa. Son las primeras constatadas en una mina prehistórica del sur peninsular y, por lo investigado hasta el momento, se completarían con las fases metalúrgicas realizadas en los propios poblados como los de El Castillejo o Peñalosa (Contreras 2000). Los otros testimonios de actividad metalúrgica en la Península Ibérica proceden de las minas de Moçissos (Portugal), de la Sierra del Aramo (Asturias) y del campamento minero de Loma de la Tejerías en Albarracín (Teruel).

En Moçissos se documentaron varios fragmentos de crisol entre la escombrera de la mina explotada desde el Calcolítico hasta el siglo XIX (Hanning et al. 2010: 289). En "La Campa les Mines" (Riosa) de la Sierra del Aramo, el ingeniero A. Dory recuperó numerosos trozos de escoria y de crisoles de arcilla refractaria con restos adheridos en su interior de "menas incompletamente reducidas" (Dory 1893: 337 y 362). Dicha información ha sido implementada en los últimos años tras los trabajos de investigación del equipo de M. de Blas. Pese al deterioro del paraje por la actividad minera industrial, se han definido estructuras datadas entre el III y II milenio ANE, como cubetas, suelos de uso/trabajo y estructuras de combustión que se vinculan tanto con el hábitat y/o estacionamiento como con el procesado del mineral de cobre (trituración y reducción) en el lugar (Blas et al. 2013). Por último, en el campamento turolense de Loma de las Tejerías, junto a una pequeña explotación minera aledaña, se halló una gota de cobre producto de la reducción de mineral de cobre (Montero y Rodríguez 2008: 163). En el resto de Europa, una de las minas mejor estudiadas con restos de metalurgia de la Edad del Bronce es la de Ross Island (Irlanda) (O’Brien 2004). 
Los contados fragmentos de vasijas de reducción hallados en la mina de José Martín Palacios, incluso a sabiendas de que la superficie excavada es exigua (un $10 \%$ de la potencia de la mina), nos permiten aventurar que proceden más bien de pruebas experimentales sobre los minerales obtenidos que de una práctica habitual y sistemática. Ello estaría en consonancia con los restos de vasijas-horno encontrados en Peñalosa y demás poblados diseminados en la zona oriental de Sierra Morena. En estos poblados sabemos que esta fase del proceso de producción metalúrgica, como las de fundición y acabado de las piezas metálicas, se realizaban por completo en los diversos ámbitos habitacionales (Contreras 2000). Sin embargo, y hasta la obtención de nuevos datos, cabe la posibilidad igualmente que la práctica de esta actividad a pie de mina dependiera de la cercanía o no de la mina a uno u otro poblado. En definitiva, estamos ante una cuestión compleja de la que se tienen escasos datos arqueológicos que esperamos la excavación en extensión de esta mina y de otras de la Península Ibérica vaya aclarando en el futuro.

La explotación de las minas de cobre de Sierra Morena oriental, entre ellas la de José Martín Palacios, y la transformación del mineral en metal supuso una intensa ocupación de este territorio durante la Prehistoria Reciente. En concreto, durante la Edad del Bronce se constata una auténtica "colonización" de la cuenca del Rumblar y del entorno de Linares. Se incrementan los asentamientos respecto a los de la Edad del Cobre, cuando se limitaban a los bordes meridionales de Sierra Morena (Nocete et al. 1987; Lizcano et al. 1990). La explotación del mineral parece conformar la base de la distribución y correlación entre los asentamientos en determinadas áreas que muestran una fuerte jerarquización y cierta especialización funcional. Encontramos fundamentalmente poblados metalúrgicos de mediano tamaño, como Peñalosa, La Verónica o Cerro de las Obras, donde se ha documentado arqueológicamente el proceso completo de transformación del mineral en metal. Son típicos poblados argáricos asentados en cerros escarpados de difícil acceso con un amplio control del territorio y de sus pasos naturales. Están interconectados visualmente directamente o a través de pequeños fortines, como el de Piedras Bermejas, que jalonan toda la cuenca fluvial, como la del Rumblar (Fig. 1). Su ubica- ción parece vincularse más bien con el control del territorio y el procesamiento y distribución del metal (Jaramillo 2005: 458 y 474) que con la distribución espacial de las minas y su explotación. Sin embargo hay poblados que se asientan en cerros muy próximos a las explotaciones mineras, como el Castillo de Burgalimar (Baños de la Encina) a la del Polígono. El de El Castillejo, el más cercano a la mina de José Martín Palacios, está escasamente a $1 \mathrm{~km}$ al Oeste, sobre el espolón que sobresale de la ladera de la mole granítica del Navamorquin. Las prospecciones realizadas en este valle documentaron varios fragmentos de vasijas metalúrgicas que demuestran su relación con el trabajo metalúrgico.

El Sondeo 5 en la mina de José Martín Palacios, situado en la cima del cerro, mostró un posible suelo o nivel de paso junto a material cerámico. Se podría asociar con un área multifuncional en la que los mineros de los poblados argáricos cercanos, desarrollarían actividades tanto cotidianas (descansar, alimentarse...), como relacionadas con los ensayos del proceso de transformación del mineral durante su trabajo estacional. En nuestro caso no tenemos evidencias arqueológicas que nos permitan hablar de la existencia de un campamento minero al estilo de los hallados en la Loma de la Tejería (Albarracín, Teruel) (Montero y Rodríguez 2008) o en "La Campa les Mines" de Sierra del Aramo (Riosa, Asturias) (Blas et al. 2013). Ahora bien los modelos de ocupación y explotación del territorio de esos territorios son totalmente diferentes al que se constata en la cuenca del Rumblar, como recordaremos, intensamente poblada durante la Edad del Bronce.

Una vez analizado el cómo y cuándo se explotaron estas minas del Polígono y de José Martín Palacios (Baños de la Encina), sería interesante analizar la cuestión de quién las explotó. Sabemos por los resultados de isótopos de plomo que el mineral de estas minas fue transformado en el poblado de Peñalosa. Pero una cuestión fundamental sería determinar si los mineros de otros asentamientos argáricos como El Castillejo, se aprovisionan igualmente allí. Otra sería documentar si el acopio de mineral, y por tanto el tiempo de laboreo, era estacional en función de las necesidades de los mineros o si existieron grupos "especializados" encargados de extraerlo $\mathrm{y}$ hacer el posterior reparto entre los diversos

Trab. Prehist., 72, N. ${ }^{\circ}$ 1, enero-junio 2015, pp. 158-175, ISSN: 0082-5638

doi: $10.3989 /$ tp.2015.12149 
poblados. Lo segundo necesariamente obligaría a prolongar la estancia en la mina.

La información arqueológica procedente de la excavación de esta mina y del estudio de la del Polígono sugiere una frecuentación humana vinculada con su explotación durante uno o varios días y no con la presencia de un campamento o asentamiento temporal (estacional durante la época estival por ejemplo), como en el caso de Loma de las Tejería o de otras minas de Europa. Los numerosos yacimientos argáricos localizados a menos de $3 \mathrm{~km}$ hacen que nos inclinemos más por la hipótesis de que fuera una práctica diaria de los habitantes de estos poblados que volverían a su lugar de origen, sin establecer un campamento. Esto no descarta que de manera puntual se instalaran varias personas durante varios días a pie de mina.

Se ha señalado anteriormente la posibilidad de que una misma mina abasteciera a más de un poblado. Los datos con que contamos, pendientes de corroboración analítica, parecen confirmarlo. La mina de José Martín Palacios abasteció de mineral a Peñalosa y es probable que también a otros poblados como El Castillejo, considerando su cercanía y el hallazgo de restos de actividad metalúrgica. También podemos afirmar que los habitantes de estos poblados se aprovisionaron en más de una mina. Los análisis de isótopos de plomo y elementales de minerales de José Martín Palacios y el Polígono confirman que los pobladores de Peñalosa se nutrieron del mineral de ambas y, al menos, del de otras dos más aún por identificar. En este caso concreto, la del Polígono sería la principal proveedora de mineral transformado en dicho poblado (7). Hasta cierto punto esto es lógico dada su cercanía (poco mas de $1 \mathrm{~km}$ ) al poblado. Ello nos lleva a pensar que la mina de José Martín Palacios fuera la principal proveedora de El Castillejo.

Se viene a corroborar así lo apuntado desde los inicios del Proyecto Peñalosa: la importancia del mineral y metal de cobre en esta formación social de la Edad del Bronce. Su desarrollo en este territorio viene marcado por una explotación a gran escala del mineral, extraído de los filones y transformado en útiles y lingotes que se move-

(7) La galena encontrada en el yacimiento de Peñalosa proviene de los sulfuros de plomo localizados en la mina del Polígono. rán posiblemente por todo el sur de la Península Ibérica (Moreno y Contreras 2010).

Por último, esta mina como la gran mayoría de los filones de esta región, tras un hiato, volvió a ser explotada en época romana como demuestra el hallazgo de material arqueológico y la documentación de dos parejas de pozos gemelos. La cerámica recuperada no nos permite afinar su cronología pero, seguramente, como la mayoría de las labores en la región, se situaría entre los siglos II a.C. y II d.C., los momentos de mayor esplendor de esta actividad productiva. El hallazgo de cerámica ebusitana evidencia la frecuentación de este cerro en época tardoantigua/bizantina, posiblemente asociada con la reexplotación de la mina. Por el momento también es difícil determinar si este filón fue explotado durante el Bronce Final y la etapa ibérica ya que no contamos con evidencias arqueológicas como para los otros dos periodos.

\section{AGRADECIMIENTOS}

El artículo se enmarca en el Proyecto General de Investigación de la Consejería de Cultura de la Junta de Andalucía, "La minería romana en Sierra Morena oriental: formas de estructuración de un territorio a partir de la producción, consumo y distribución de los metales" (PGI, 2012-2017), dirigido por Luis Arboledas Martínez, y en el Proyecto $\mathrm{I}+\mathrm{D}+\mathrm{i}$, "La minería en el Alto Guadalquivir. Formas de construcción histórica en la antigüedad a partir de la producción, consumo y distribución de los metales" (HAR2011-30131-C02-01), dirigido por Francisco Contreras Cortés. Asimismo, este trabajo se ha realizado gracias al contrato como Investigador JAE doc postdoctoral de Luis Arboledas Martínez, cofinanciado por el Fondo Social Europeo.

En este punto es justo y necesario dar las gracias a una serie de personas y entidades que de una y otra forma han facilitado el desarrollo de esta intervención: al Ayuntamiento de Baños de la Encina y a su Alcalde, D. Antonio de las Heras Cortés por su gestión y apoyo logístico y la financiación de tres operarios; al propietario de la Finca de Doña Eva, D. Pablo Vallejo Navarro, y al guarda de la misma, D. Alfredo Limón, por permitirnos la realización de la excavación, facilitarnos el acceso a la propiedad y ayudarnos en 
todo lo necesario; a D. José Dueñas, D. Antonio Ángel García, D. José Susi, miembros del Colectivo Proyecto Arrayanes, y D. Álvaro Gómez García por ayudarnos en la exploración del pozo y por realizar la topografía del cerro; a nuestra amiga y compañera Dña. Margarita Sánchez Romero por llevar a cabo la digitalización del dibujo arqueológico; por último y no por ello menos importante, a Salvador Rovira Llorens por su inestimable colaboración en la interpretación de los resultados analíticos de los restos minero-metalúrgicos de la mina de José Martín Palacios-Doña Eva.

\section{BIBLIOGRAFÍA}

Acosta, P. 1995: "Las culturas del neolítico y calcolítico en Andalucía Occidental". Espacio, Tiempo y Forma 8: 33-80.

Ambert, P. 1994: "Les mines préhistoriques de Cabrières (Herault): Quinze ans de recherches. État de la question". Bulletin de la Société Préhistorique Française, 92 (4): 499-508.

Ambert, P.; Carozza, L. y Léchelon, B. 1998: "De la mine au métal au sud du Massif Central au Chalcolithique (région de Cabrières, Fayet et Villefranche de Rouergue)". En C. Mordant, M. Pernot y V. Rychner (eds.): L'atelier du bronzier en Europe du XXe au VIle siècle avant notre ère, Actes du colloque international Bronze'96, Neuchâtel et Dijon, II: 59-69 Paris.

Arboledas, L. 2010: Minería y metalurgia romana en el Sur de la Península Ibérica: Sierra Morena oriental. British Archaeological Reports, International Series 2121. Archaeopress. Oxford.

Arboledas, L. y Contreras, F. 2010: "La mina del Polígono o Contraminas (Baños de la Encina, Jaén). Evidencias de la explotación de mineral de cobre en la antigüedad". Cuadernos de Prehistoria y Arqueología de la Universidad de Granada 20: 355-379.

Arboledas, L.; Contreras, F.; Dueñas, J.; Pérez, A. A. y Moreno, A. 2008: "La minería romana en la cuenca del río Rumblar: la mina de José Martín Palacios". En A. Palacios, J. Escribí y P. L. Higueras (eds.): Actas VII Congreso Internacional sobre Patrimonio Geológico y Minero (Puertollano 2006): 391-406. Puertollano

Arboledas, L.; Contreras, F.; Moreno, A.; Dueñas, J. y Pérez, A. A. 2006: "La mina de José Martín Palacios (Baños de la Encina. Jaén). Una aproximación a la minería antigua en la cuenca del Rumblar". Arqueología y Territorio 3: 179-195.
Blanco, A. y Rothenberg, B. 1981: Exploración Arqueometalúrgica de Huelva. Editorial Labor. Barcelona.

Blas, M. A. de 1996: "La primera minería metálica del norte peninsular: las indicaciones del C-14 y la cronología prehistórica de las explotaciones cupríferas del Aramo y El Milagro". Complutum Extra 6 (I): 217-226.

Blas, M. A. de 2007-2008: “Minería prehistórica del cobre en el reborde septentrional de los Picos de Europa: las olvidadas labores 'El Milagro' (Onís, Asturias)". Veleia 24-25: 723-753.

Blas, M. A. de; Rodríguez del Cueto, F. y Suárez, M. 2013: "De las labores subterráneas a las actividades metalúrgicas en el exterior: Investigaciones 2007-2012 en las minas de cobre prehistóricas de la Sierra del Aramo ("La Campa les Mines", Concejo de Riosa)". Excavaciones arqueológicas en Asturias 2007-2012. En el centenario del descubrimiento de la caverna de la Peña de Candamo. Consejería de Cultura y Turismo del Gobierno del Principado de Asturias. Oviedo: 169-187.

Blas, M. A. de y Suárez, M. 2009: "Investigaciones arqueológicas de 2005 y 2006 en las minas de cobre prehistóricas de la sierra del Aramo, Texéu (Riosa)". Excavaciones arqueológicas en Asturias 2003-2006. Consejería de Cultura y Turismo del Gobierno del Principado de Asturias. Oviedo: 421-435.

Bronk Ramsey, C. 2009: "Bayesian Analysis of radiocarbon dates". Radiocarbon 51 (1): 337-360.

Chernykh, E. N. 2004: "Kargaly: the largest and most ancient metallurgical complex on the border of Europe and Asia". En K. M. Linduff (ed.): Metallurgy in Ancient Eastern Eurasia from the Urals to the Yellow River. Edwin Mellen Press. Lewiston: 223-238.

Contreras Cortés, F. (ed.) 2000: Proyecto Peñalosa. Análisis histórico de las comunidades de la Edad del Bronce del Piedemonte Meridional de Sierra Morena y Depresión Linares-Bailen. Arqueología Monográficas 10, Dirección General de Bienes Culturales. Sevilla.

Contreras, F. y Dueñas Molina, J. (ed.) 2010: La minería y la metalurgia en el Alto Guadalquivir: desde sus orígenes hasta nuestros dias. Instituto de Estudios Giennenses, Diputación Provincial de Jaén. Jaén.

Contreras, F.; Dueñas, J.; Jaramillo, A.; Moreno, A.; Arboledas, L.; Campos, D.; García, J. A. y Pérez, A. A. 2005: "Prospección arqueometalúrgica en la cuenca alta del río Rumblar". Anuario Arqueológico de Andalucía 2002, II Actividades Sistemáticas: 22-36.

Craddock, P. T. 2013: "Local traditions and foreign contacts: innovation in Tartessian metallurgy". En J. M. Campos y J. Alvar (eds.): Tartesos. El emporio del metal. Editorial Almuzara, s.1.: 417-447.

Domergue, C. 1983: La mina antique d'Aljustrel (Portugal) et les Tables de Bronze de Vipasca. Editorial de Boccard. Paris. 
Domergue, C. 1990: Les mines de la Péninsule Ibérique dans l'antiquité romaine. Collection de l'Ecole Française de Rome 127. Ecole Française de Rome. Rome.

Dory, A. 1893: "Las minas antiguas de cobre y cobalto del Aramo". Revista Minera y de Ingeniería 1463: 332-337; 1466: 361-366.

García Romero, J. 2002: Minería y Metalurgia en la Córdoba romana. Universidad de Córdoba. Córdoba.

Hanning, E.; Gauß, R. y Goldenberg, G. 2010: "Metal for Zambujal: experimentally reconstructing a 5000-year-old technology". Trabajos de Prehistoria 67 (2): 287-304.

Hunt, M.; Contreras, F. y Arboledas, L. 2011: "La procedencia de los recursos minerales metálicos en el poblado de la Edad de Bronce de Peñalosa (Baños de la Encina, Jaén). Resultados de análisis de isótopos de plomo". Actas del V simposio internacional sobre minería y metalurgia históricas en el suroeste europeo, Homenaje a Claude Domergue (León 2008): 197-208. Lérida.

Jaramillo, A. 2005: Recursos y materias primas en la Edad del Bronce del Alto Guadalquivir, medioambiente y el registro arqueológico en la cuenca del río Rumblar. Dpto. de Prehistoria y Arqueología, Universidad de Granada. Granada. http://www.academia.edu/3178889/ Recursos_y_materias_primas_en_la_Edad_del_ Bronce_del_Alto_Guadalquivir_medioambiente_y_ registro_arqueol\%C3\%B3gico_en_la_cuenca_ del_r\%C3\%ADo_Rumblar (consulta $21-\bar{X} I I-2014)$.

Lizcano, R.; Nocete, F.; Pérez, F.; Contreras, F. y Sánchez, M. 1990: "Prospección arqueológica sistemática en la cuenca alta del río Rumblar". Anuario Arqueológico de Andalucía 1987 II. Actividades Sistemáticas: 51-59.

Llul, B.; Perelló, L.; Hunt, M.A.; Perelló, D. y Salvá, B. 2012: "L'explotació prehistórica dels recursos cuprífers s'Illa den Colom (Maó, Menorca)". IV Jornades d'Arqueologia de les Illes Balears (Eivissa, 2010): 11-17. Eivissa.

Montero Ruiz, I. 2010: "Minería y metalurgia en la investigación prehistórica”. En I. Montero Ruiz: Manual de arqueometalurgia. Museo Arqueológico Regional de Madrid. Alcalá de Henares: 53-86.

Montero, I.; Rafel, N.; Hunt, M. A.; Mata, J. M.; Odriozola, C.; Soriano, I. y Murillo, M. 2012: "Minería prehistórica en el Priorato: caracterización arqueométrica de minas de Cornudella, Alforja y
Ulldemolins". VII Congreso Internacional sobre minería y metalurgia históricas en el Sudoeste europeo (Utrillas, 2012): 131-140. Teruel.

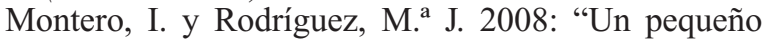
campamento minero de la Edad del Bronce: la Loma de la Tejería (Albarracín, Teruel)". Trabajos de Prehistoria 65 (1): 155-168.

Moreno, A. y Contreras, F. 2010: "La organización social de la producción metalúrgica en las sociedades argáricas: el poblado de Peñalosa". Menga 1: 53-76.

Moreno, A.; Contreras, F.; Renzi, M.; Rovira, S. y Cortés, H. 2010: "Estudio preliminar de las escorias y escorificaciones del yacimiento metalúrgico de la Edad del Bronce de Peñalosa (Baños de la Encina, Jaén)". Trabajos de Prehistoria 67 (2): 305-322.

Nocete, F.; Sánchez, M.; Lizcano, R. y Contreras, F. 1987: "Prospección arqueológica sistemática en la cuenca baja/media-alta del río Rumblar". Anuario Arqueológico de Andalucía 1986, II Actividades Sistemáticas: $75-78$.

O'Brien, W. 2004: Ross Island. Mining, Metal and Society in Early Ireland. Bronze Age Studies 6, Departament of Archaeology, National University of Ireland. Galway.

Perelló, L.; Llull, B.; Salvà, B. y Hunt, M. A. 2013: "Sa Mitja Lluna: una mina de coure de l'edat del bronze". Revista Ambit 29. http://www.cime.es/WebEditor/Pagines/file/Ambit/Gener2013/ArticlerevistaAmbitV2.pdf. (consulta 4-II-2014)

Reimer, P. J.; Bard, E., Bayliss, A.; Beck, J. W.; Blackwell, P. G.; Bronk Ramsey, C.; Grootes, P. M.; Guilderson, T. P.; Haflidason, H.; Hajdas, I.; HattŽ, C.; Heaton, T. J.; Hoffmann, D. L.; Hogg, A. G.; Hughen, K. A.; Kaiser, K. F.; Kromer, B.; Manning, S. W.; Niu, M.; Reimer, R. W.; Richards, D. A.; Scott, E. M.; Southon, J. R.; Staff, R. A.; Turney, C. S. M. y van der Plicht, J. 2013. "IntCal13 and Marine 13 Radiocarbon Age Calibration Curves 0-50,000 Years cal BP". Radiocarbon 55(4): 1869-1887.

Rovira Llorens, S. y Martinez Navarrete, M. I. 2005: "Kargaly, esplendor minero en la Edad de Bronce". Tierra \& Tecnología. Revista de actualidad e información geológica 27: 29-38.

Timberlake, S. 2003: Excavations on Copa Hill, Cwmystwyth (1986-1999). An Early Bronze Age copper mine within the uplands of Central Wales. British Archaeological Reports, British Series 348. Achaeopress. Oxford. 